\title{
Making Justice More Accessible
}

\author{
Davide Carneiro \\ CCTC/Department of Informatics \\ Universidade do Minho \\ Braga, Portugal \\ +351253604437 \\ dcarneiro@di.uminho.pt
}

\author{
Paulo Novais \\ CCTC/Department of Informatics \\ Universidade do Minho \\ Braga, Portugal \\ $+351253604437$ \\ pjon@di.uminho.pt
}

\begin{abstract}
From the point of view of the Citizen, Justice is not always readily accessible. Either because it is a lengthy process, potentially expensive, sometimes unclear or simply scary, people will often avoid or withdraw from a judicial process, especially in those cases that involve relatively small amounts. This results in the giving up of a basic right, with the potential loss of rightful benefits. In this paper we briefly analyze the main aspects that impair access to Justice nowadays. We then move on to look at recent technological developments in the field of Online Dispute Resolution to argue that these can, in the near future, have a significant role in improving access to Justice. Specifically, we analyze the UMCourt Conflict Resolution Framework, developed by our research team, and address the different dimensions in which such tools contribute to make Justice more accessible, namely through better access to useful information, support in decision-making or more cost-effective processes.
\end{abstract}

\section{Categories and Subject Descriptors}

I.2.1 [Artificial Intelligence]: Applications and Expert Systems law, office automation.

H.3.5 [Information Storage and Retrieval]: Information Search and Retrieval - information filtering, relevance feedback, retrieval models, search process, selection process.

\section{General Terms}

Algorithms, Management, Human Factors, Legal Aspects.

\section{Keywords}

Online Dispute Resolution, Accessibility, Citizen Empowerment.

\section{INTRODUCTION}

Access to Justice for every citizen is not only a basic human right but also a key element of democratic governance. Until recently, access to Justice implied the presence of individuals at a specific place and time and in a specific environment. These "events", which constitute the steps of a generally well-defined and established process, usually lead to a final stage of litigation in the courtroom. Traditionally, there is thus the need for parties, attorneys, juris and other members of the legal staff to meet several times, which may sometimes be difficult and encompass direct economic costs (e.g. traveling) as well as indirect (e.g. absence from work).

This is just one of the many issues that led to the necessity for alternatives that could be more appealing both for the legal systems and the parties involved as well as improve citizen access to justice. In the last decades this resulted in the emerging of the so-called Alternative Dispute Resolution [1], including methods to solve disputes outside the traditional circles, in which the figure of the mediator or arbitrator gains a central role over the one of the courtroom. In fact, Alternative Dispute Resolution methods have since its inception been looked at as a possible mean of improving access to justice [2].

More recently, Online Dispute Resolution [3] gained notoriety as the application of similar procedures partly or wholly in an online setting or with the support of telematics. This means that, for the first time, people no longer necessarily need to meet in a specific time or space in order to solve a conflict. Online Dispute Resolution is most likely the most visible face of the e-justice movement, which is one of the pillars of e-government [21].

Alternative Dispute Resolution, especially in its online form, can thus play a very important role in improving the access of citizens to justice, in which the facilitation of meetings is just one of the aspects, others being process costs and time.

In this paper we look specifically at this topic by identifying the current main barriers in the access to justice. We analyze how technology, particularly in the domain of Online Dispute Resolution, can help citizens in overcoming some of these barriers. This descriptive work is the result of several years or research and development of solutions in the domain of Online Dispute Resolution.

We start by analyzing some of the most significant barriers in Section 2, and briefly introducing Alternative and Online Dispute Resolution in Section 3. Subsection 3.1 is devoted to UMCourt, a specific Conflict Resolution Platform embodying Artificial Intelligence techniques. Section 4 exposes the different ways in which this and similar technological tools can improve the access of the common citizen to justice. The paper ends with the concluding remarks of Section 5.

\section{CURRENT BARRIERS IN THE ACCESS TO JUSTICE}

Although it can be considered a basic Human right, access to justice is not granted to every citizen. Deborah Rhode, upon analyzing this problem in the North American context, puts it in this terms: "Millions of Americans lack any access to justice, let alone equal access. Worse, the increasing centrality of law in American life and its growing complexity has made access to legal assistance critical for all citizens." [4].

There are some groups that face particular barriers. These groups include people that are generally unaware of their rights, commonly elderly people or people living in more isolated areas or areas with less access to information. The lack of accessible transportation, lack of services or physical barriers are also issues that can be particularly harming for this slice of the population, as well as for people with certain disabilities. Still concerning 
elderly, the ones that live alone with reduced autonomy or that live in care homes and depend on the care of a provider (which is often the single contact point with the exterior world) are also at risk. People with low income may find it difficult to access justice as it often represents significant costs $[5,4]$. There are many other cases which may be harder to address, such as the case of children who live under the custody of an adult (that conditions their access to information and services) that abuses them, or the cases of immigrants (especially illegal immigrants) who will hardly be able to access justice if they need. Gender may also be another discriminating factor, with women facing greater barriers than men in certain countries such as India or Haiti [6].

Given the broad nature and complexity of barriers in the access to justice, we will focus on some of the drawbacks of current conflict resolution mechanisms, for which we can propose concrete solutions. These can, from our point of view, be organized in two main groups as they have different sources and require potentially different strategies to address them: (1) drawbacks inherited from the current state of judicial systems and (2) drawbacks related with the current approaches on alternative conflict resolution methods. Indeed, while Alternative and Online Dispute Resolution emerged to address some of the problems of litigation in court, these are not without drawbacks themselves.

In this section we systematically analyze the main problems identified and point out their main causes. Based on this, possible technological solutions to the problems will be considered, which are analyzed in more detail in the following section, in the framework of a concrete Conflict Resolution Platform.

Concerning the issues that derive from the current state of judicial systems, the main problem may be stated as follows: they are very slow and very expensive. A list of causes and their relationships are now put forward, also depicted in Figure 1.

1. Uncooperative environments - Courtrooms are highly uncooperative environments in which parties have as main objective to gain their cases, at the expenses of the other side. These classical win-lose scenarios, common in the courtroom, hinder the achievement of a mutually agreeable outcome, with consequences on cause 2). Moreover, parties are often afraid of the mere idea of going into a courtroom and avoid dealing with the conflict at all;

2. Numbers of appeals - Defendants have the right to appeals, which is a manifestation of their increasing rights. However, it is also one of the major causes for the low throughput of courtrooms, as each appeal adds to the amount of time needed and costs associated to resolve a case, with outcomes being delayed further. The lengthiness of the process is often the reason for the decision of a party not to initiate a litigation, especially in those cases which involve small values;

3. Increasing new cases - Currently every minor action is liable to end up in court, independently of the costs involved. A significant amount of these processes involves small-value claims resulting from the number of exponentially increasing e-Commerce transactions. Unfortunately, the time to conclude the process is not proportional to the value of the claim;

4. Increasing rights - Defendants have increasing rights, which is undoubtedly the reflection of a positive evolution of the legal systems. Nonetheless, this also contributes to the aggravation of the problems of judicial systems, mainly when concerned with points 5) and 6);

5. Complexity of legal systems - Legal systems are becoming increasingly complex due to the increase in the number and complexity of rules, the existence of several ways to do similar things, the use of specialist terms and specialized language, the rapid appearance of new concepts or the increasing amount of information in each case, just to name a few. This makes the analysis of each individual claim more complex, costly and lengthy, which often scares parties away from a litigation process;

6. Complexity of cases - Each legal process is becoming increasingly complex due to a need for a more precise specification of each word, decision or rule used. The emergence of new (legally challenging) concepts and the easiness with which proof is managed and presented electronically also adds to this problem;

7. Costs of legal practitioners - Although the legal system and some of the parties may divide the costs of a legal process, they still tend to be significant. They include the costs of the whole court staff (e.g., clerk, administration, security, legal staff, support staff, court reporter), solicitor fees, disbursements, lawyer services (generally paid hourly), document management or transportation, among others.

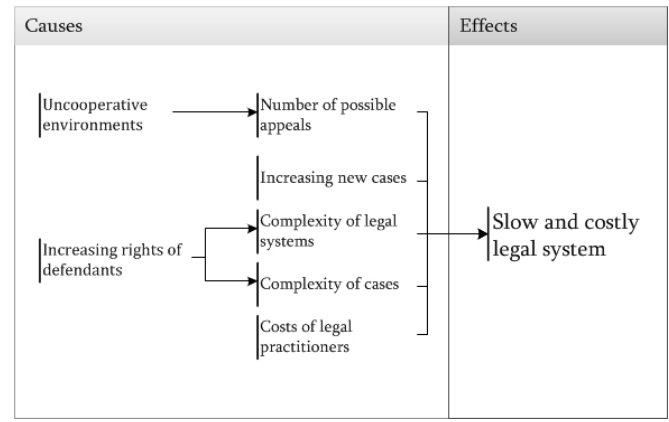

Figure 1. The main causes and effects identified in the current state of judicial systems.

The issues pointed out previously concern only barriers that stem from the litigation process, and especially those related to the slowness and cost of the process. Let us now focus on the issues related to Online Dispute Resolution since, despite its advantages, it may also encompass barriers to its user. Other problems are thus identified:

1. Richness of online communication - Depending on the communication mean, communicating online poses new challenges, as the lack of contextual information (e.g., body language or associated functional answers), which may threaten the efficiency of the communication process. Misunderstandings are frequent and are particularly frightening in the legal domain as they can result in harmed relationships. People that find it difficult to communicate online, either for lack of experience or some other disability are particularly at risk;

2. Info-exclusion - The lack of training in the generic use of technological tools poses an obstacle to the use of ODR mechanisms. Complex or unfriendly user interfaces are other common deterrents that can result in an unbalance between the parties when using the ODR tool. People with poor access to training in the use of technology, namely the 
elderly, may find this to be a significant barrier. People living in areas with poor access to Information and Communication technologies are also harmed;

3. Costs of ODR - The use of ODR is generally cheaper than litigation, but it is not necessarily inexpensive. Besides the fees to use a given ODR service, additional costs may exist such as the cost of the access to the technology (e.g., internet, computer), particularly significant in developing countries. This may result in an imbalance between the parties (e.g. when one has cheaper and easier access to technology) and in a barrier to access these services (e.g. when the party must pay access to communication technologies in proportion to the time used);

4. Security, privacy, data protection and identity - These issues are not specifically related to ODR but rather result from the use of online communication methods and online tools. Nevertheless, they reasonably constitute one important concern in a field such as the legal one. People are increasingly worried about these issues and may look with suspicion at the providing of sensitive information in an online setting, refraining from the (partial or full) use of the conflict resolution platform;

5. Rudimentary access to information - ODR tools frequently have data access methods that are tightly coupled with the data representation layer, providing no abstraction and making it difficult for the parties to efficiently understand and manage the data;

6. Rudimentary conciliation methodologies - Conciliation methodologies in ODR frequently place emphasis on human factors and depend significantly on the parties' decisions and judgment. This lack of a formal structure may result in a sense of disorganization as well as in longer processes and less successful processes. In fact, some people may find this informality harmful and look at it as a barrier to them getting to the best possible outcome, preferring to resort to the court which provides an established and widely used method for conflict resolution (thus at principle more trustworthy);

These problems are also rooted in a number of concrete causes, which are described next and depicted in Figure 2.

1. Lack of body language - Body language is one of the most important communication modalities. Our gestures, our posture, our attitudes or our facial expressions provide the necessary framework for our interlocutors to correctly understand our own words. The lack of this information significantly hinders communication;

2. Lack of contextual factors - There are other modalities involved in communication besides the ones mentioned in 1). These modalities include the physiological response of our body, the rhythm of the speech, the tone of the voice or the accentuation. The lack of such modalities in online communication negatively affects it;

3. Lack of training - Even today there are people who are ill at ease with the use of the technological tools that support ODR. This factor, as well as the lack of specific training or support in using a given tool, may make it difficult for parties to efficiently use an ODR environment;

4. Non-intuitive interfaces - Many ODR tools available nowadays still rely largely on traditional web forms and static pages as an interface for information. This may pose an obstacle, mainly when they are not adapted to the specific context or to the needs/characteristics of the users;

5. Cost of access to technology - There are costs associated to the use of technological solutions that, although not dependent on the ODR approach, are inherent to their use. These costs may include the costs of the hardware necessary as well as the costs of using the necessary telecommunication channel (e.g., internet or a telephone service provider);

6. Fee for using tools - Although ODR tools tend to be less expensive than traditional litigation, their use may be subject to a fee (fixed or per unit of time), which may amount to a significant sum. Moreover, the use of conciliation services mediated by a neutral mediator also tends to have an associated fee;

7. Information security in online environments - The sheer fact of communicating online rises issues related, namely, to online identity (how am I sure that I am talking to whom I think I am?), privacy (how do I know that my information would not be accessed by someone who should not access it?) or data protection (how do I know that my personal data will not be available to anyone else?). Although these issues are transversal, they are particularly worrying in the legal domain;

8. Low level access to data - Data representation models tend to be very close to the data layer. Representing information as it is stored, without abstraction methods, makes it difficult for parties to efficiently understand and manage it;

9. Lack of structure/formalization - Many ODR processes, despite taking place in online environments, are still largely unstructured. This informal approach, largely human-based, which on the one hand results from the flexible nature of ODR, may also result in difficulties for taking decisions, for managing information and for following some desirable line of attack or strategy;

10. Highly human-dependent interaction methods - Interaction methods in ODR tools still rely largely on natural language and on the rhythm or pace that the participants impose. Moreover, they focus too much on subjective issues such as the parties' personal views on the problem. This hampers the use of tools to support conciliation;

The current main problems in judicial litigation and ODR as well as their causes have been put forward. The issues mentioned were compiled from a revision of the current state of the art in the legal systems as well as from an analysis of several commercial ODR providers and research projects [24].

Based on this study, several solutions that would contribute to the improvement of the current state of affairs are put forward. These solutions constituted the foundation for the definition and steering of the work that resulted in the development of the UMCourt Conflict Resolution Platform, detailed in the following section. A brief description of each potential solution is given below.

These solutions can be grouped in three main categories, according to their scope, namely: (1) everyday justice, including tools to provide better access to information and manage disputes in the community; (2) informal justice, including assistance to solve disputes outside the courtroom; and (3) formal justice, including courts and tribunals. 


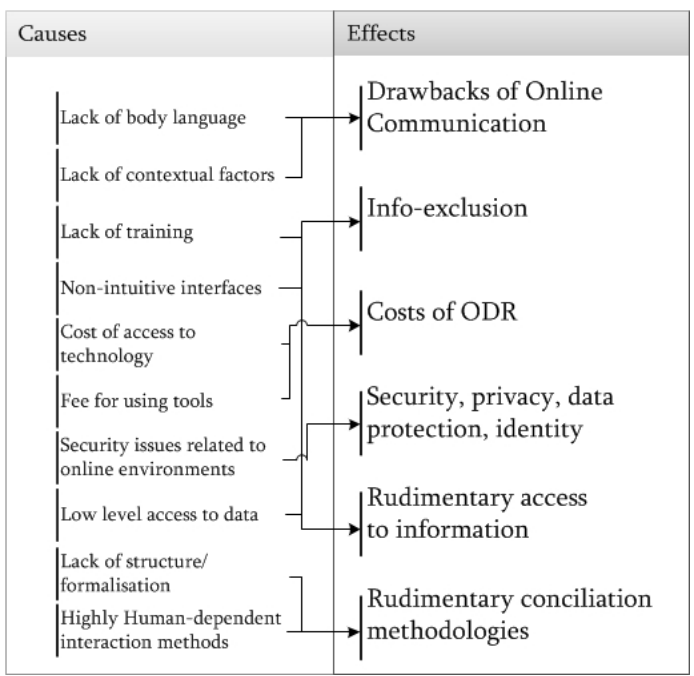

Figure 2: The main problems and their causes identified in current Online Dispute Resolution tools.

1. Development of autonomous solutions - The development of technological solutions that may, to some extent, alleviate the work of human practitioners could have positive effects on the efficiency of the legal systems. On the one hand, it could allow for legal practitioners to work more efficiently and with increased quality, by freeing them from monotonous and repetitive tasks. This would have an impact on the throughput of conflict resolution approaches, making them more efficient. Consequently, operating and specialistrelated costs would be reduced. On the other hand, this would also allow to reduce the apparent complexity of legal problem-solving, potentially making it more intuitive and supportive;

2. Improvement of Communication Environments - A positive and cooperative communication environment is paramount in the implementation of efficient conciliation approaches. The development of communication environments that look at contextual information such as body language, as a communication modality, may allow to improve the efficiency of the simple "message passing" approaches used nowadays. Moreover, such approach would allow mediators working behind a computer to better understand the state of the parties, allowing a better management of the process (e.g., making a pause when a party shows signs of stress or fatigue). It would have a positive effect on the success rate of conflict resolution processes, under the assumption that people that communicate will understand each other's fears and objectives better, will cooperate more willingly and will consequently be more likely to work together towards a solution. A particularly important subject here is the level of stress as an indicator of the inclination of a given party towards undesired behaviors, such as hasty decisions, loss of interest, rudeness in communication or giving up the process. Mediators could take profit of the access to this information in order to better manage the process;

3. Improve generation of solutions/strategies - Not infrequently, the main obstacles to conflict resolution reside within the parties themselves. The generation of solutions, which is often the responsibility of the parties (especially in alternative conflict resolution approaches), is an example of a potential problem, since most of us are not familiar with the action of devising a solution for a given problem (or we are simply not willing to), namely when it includes complex issues with complex relationships. The definition of a potentially successful strategy may be even more challenging. Nevertheless, these two features are central in the conflict resolution process. Tools to support them are necessary, and may improve the quality of the solutions/strategies used;

4. Improve information available to parties - In order for an individual to take good decisions he/she must be able to analyze different courses of action, weight their possible outcomes, decide on one over the others and learn from the consequences of that choice. This can nevertheless be challenging without the right amount of information with a minimum level of quality. The lack of these conditions implies that individuals take decisions based on incomplete or poor information, being most likely far from optimum. Tools for compiling information are thus needed and may provide concise and useful data for the parties involved in a conflict resolution process to take realistic and weighted decisions, that will be more likely to be accepted by other parties;

5. Pre-claim conciliation - Currently many of the processes pending in courtrooms involve small-value claims that can nevertheless make their way through different courts by means of consecutive appeals, making judicial processes inefficient. The parties should see pre-claim conciliation as a potential way to a faster and cheaper resolution of their differences. Successful alternative conflict resolution methods could thus not only improve the satisfaction of the parties by allowing them to solve their problems more efficiently, but also contribute to the decrease the main problem of litigation currently;

6. Decision Support Systems - Decisions in the legal domain are frequently multi-issue, multi-value and multi-party with complex relationships between these variables, generally hardly to understand at first sight. Parties thus need support in analyzing their possible choices in real time and understand the relationship between them and their consequences. Tools to support parties under this setting not only contribute to more adequate decision processes but also to induce a more structured and formal way of reasoning and taking decisions in the legal arena.

\section{ALTERNATIVE AND ONLINE DISPUTE RESOLUTION}

In the search for efficient and valid alternatives to traditional litigation in courts that could attenuate the disadvantages mentioned in the precious section two main trends have emerged: Alternative Dispute Resolution and Online Dispute Resolution.

Alternative Dispute Resolution includes methods such as mediation, negotiation or arbitration that aim at putting the parties into contact, establishing points of agreement and peacefully solving the conflict away from the courtroom. Online Dispute Resolution, on the other hand, aims not only at using such methods in virtual environments but also at the development of technology-enabled tools that can improve the work of legal practitioners and the role of the parties on the whole process. 
Several methods of ADR may be considered, "from negotiation and mediation to modified arbitration or modified jury proceedings" [7]. In a negotiation process the two parties meet each other and try to obtain an agreement by conversation and trade-offs, having in common the willing to peacefully solve the conflict. It is a non-binding process, i.e. the parties are not forced to accept the outcome. In a mediation process the parties are guided by a third neutral party, chosen by both, that acts as an intermediate in the dispute resolution process. As in negotiation, it is generally not a binding process, unless agreed otherwise. At last, the arbitration process, which is the one most similar to litigation. In arbitration a third independent party hears the parties in conflict and, without their intervention, decrees a (usually) binding outcome.

Although Alternative Dispute Resolution methods represent an important step to keep processes away from courts, there is still the need for a physical and temporal location in which the parties can meet, which may sometimes be difficult or event impracticable, especially in the non-rare situations in which parties are from different and geographically distant locations.

This, together with the natural technological evolution initiated in the previous century, led to another approach, one that uses the advantages of already traditional Alternative Dispute Resolution methods and, at the same time, relies in the information technologies for bringing the parties closer together, even in a virtual way: Online Dispute Resolution.

Online Dispute Resolution uses new information technologies like instant messaging, email, video-conference, forums, and others to put parties into contact, allowing them to communicate from virtually anywhere in the world.

The most basic settings of ODR systems include legal knowledge based systems acting as simple tools to provide legal advice, systems that try to put the parties into contact and also "systems that (help) settle disputes in an online environment" [8].

However, these rather basic systems can be extended, namely with insights from the fields of Artificial Intelligence, specifically agent-based technologies and all the well-known advantages that they bring along. A conflict-resolution platform incorporating such concepts will no longer be a passive platform that simply concerns about putting the parties into contact [9]. Instead, it will start to be a dynamic platform that embodies the fears and desires of the parties, accordingly adapts to them, provides useful information on time, suggests strategies and plans of action and estimates the possible outcomes and their respective consequences.

It is no longer a mere tool that assists the parties but one that has a proactive role on the outcome of the process. This approach is clearly close to the second generation ODR envisioned by Chiti and Peruginelli as it addresses the three characteristic enumerated in [9]: (1) the aim of such platform does not end by putting the parties into contact but consists in proposing solutions for solving the disputes; (2) the human intervention is reduced and (3) these systems act as autonomous agents. The development of Second Generation ODR, in which an ODR platform might act "as an autonomous agent" [9] is indeed an appealing way for solving disputes.

Online Dispute Resolution is therefore more than simply representing facts and events; a utile software agent that performs useful actions, also needs to know the terms of the dispute and the rights or wrongs of the parties [9]. Thus, software agents have to understand law and/or and processes of legal reasoning and their eventual legal responsibility [10].

This type of approach environment thus goes much further than just transposing ADR ideas into virtual environments; it should actually be "guided by judicial reasoning", getting disputants "to arrive at outcomes in line with those a judge would reach" [11].

\subsection{UMCOURT}

UMCourt is the Conflict Resolution Platform that resulted from the TIARAC project - Telematics and Artificial Intelligence in Alternative Conflict Resolution. This Portuguese funded project aimed at developing tools for supporting several aspects of Conflict Resolution, based on techniques from Artificial Intelligence. The integration of these tools into a single service framework resulted in UMCourt, further described and evaluated in [18].

UMCourt addresses many different aspects of what could be expected from a Conflict Resolution Platform, ranging from the most low-level ones concerning the management and functioning of the platform itself to high-level ones such as the compilation of important information about the cases and the parties, to support decision-making.

It is based on the Multi-agent Systems paradigm [12]. Under this paradigm, a large system, in this case one aiming at supporting conflict resolution, is built on the interaction of elements of smaller scale and complexity. Each of these elements, the software agent, has a set of goals (which in a cooperative system such as this one may include collective goals), constraints and a degree of autonomy that allows it to take decisions that maximize its chance of achieving these goals.

Specifically, UMCourt is based on the JADE agent framework [13], which aims at the simplification of the development of multi-agent systems by providing support for agent communication and registry. The platform runs on a Java Virtual Machine, thus agents are also programmed using the Java language.

The agents that make up the architecture of UMCourt were organized on a set of layers. The agents in each layer implement functionalities that are interrelated. One important aspect of this architecture is that it can be extended to different legal domains with relatively small amount of work and, most importantly, without making changes to the existing architecture. To accomplish this, abstract processes and concepts were identified, which are valid in most of the legal domains, and implemented through abstract process models, as described in more detail in [14].

\section{MAKING JUSTICE MORE ACCESSIBLE THROUGH TECHNOLOGY}

Based on the solutions put forward in Section 2 to address the identified prolems and on the architecture and functionalities of the conflict resolution platform described in the previous section, let us now concretely state how such platform, as well as similar approaches, can contribute to improving citizen access to justice. We address four main topics in the following sub-sections: (1) improving access to important information that can be used by the parties to take better decisions and know their case in full detail; 
(2) the support of decision-making, namely during the negotiation process; (3) compilation of contextual information about the parties and their case; and (4) the decreasing of costs in several ways. Let us stress once again that all this section is written focusing on the notion of Alternative Conflict Resolution, especially technology-supported, always in an attempt to avoid the courtroom.

\subsection{Improving Access to Important Information}

In a dispute resolution process it is important to: (1) provide the parties with useful and important knowledge about the dispute and (2) potentiate the role of the parties throughout all the process. In fact, parties that have poor access to important information generally make bad choices or, at least, they hardly make the best ones. Moreover, if parties do not understand fully the aspects of the case and the conflict resolution process, they may feel a lack trust.

An important step is thus to identify the knowledge that is meaningful for the parties and to provide them with such information so that they can feel comfortable during the process. In a first instance, it would be interesting for a party to determine to which extent is it reasonable to engage in a dispute resolution process, that is, are there any significant advantages against litigation and if the parties can reach the best outcome using an alternative dispute resolution. It has been abundantly pointed out in the literature the relevance of BATNA - Best Alternative to a Negotiated Agreement for ADR / ODR, or the possible best outcome "along a particular path if I try to get my interests satisfied in a way that does not require negotiation with the other party [15]". In ODR environments, through the use of datamining techniques, semantic web technology or other techniques used to calculate BATNA, the parties should be able to foresee the possible outcome of the judicial dispute in case of not reaching an agreement through ODR.

However, the use of BATNA alone may not be enough as parties will often tend to underestimate the probabilities of an undesired result in judicial litigation [8]. In that sense, important knowledge also includes the WATNA - Worst Alternative to Negotiated Agreement, the ZOPA - Zone of Possible Agreement, as proposed by Raiffa [16], or the MLATNA - Most Likely Alternative to a Negotiated Agreement [17], computed in the UMCourt according to a case-based approach [18]

It is also important for parties to have access to past cases, so that they can analyse them and gain a better understanding about the domain of the problem. However, it does not matter so much which is the most likely outcome (which might be hard to estimate, although being possible to introduce metrics in order to measure the probabilities of each outcome), but rather to foresee the real risks that the parties are facing - the extreme value presented by WATNA may well force the parties to change their ideas about their BATNA and ZOPA. Following the same line of thought, we can additionally state that the existence of metrics that measure the probability of each possible outcome could also be extremely useful for a party in an attempt to understand how likely each scenario is [19]. This knowledge can be used not only to correctly inform the parties (as shown in Figure 3) but also to support other functionalities of the conflict resolution platform. Specifically, in this kind of knowledge is used to allow the estimation of the personal conflict styles, as depicted in Section 4.3.

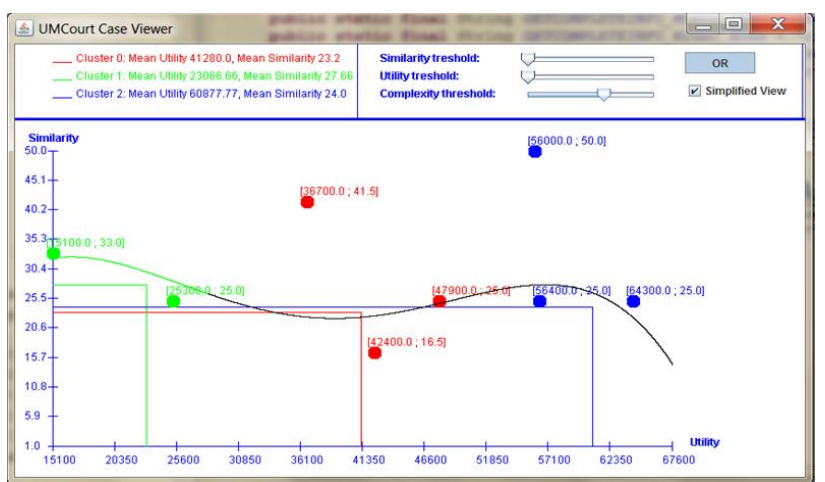

Figure 3. Graphical representation of the information compiled.

It is our conviction that conflict resolution platforms that are able to produce and provide this kind of information will improve citizen access to justice in the sense that they will make access to meaningful information easier and more transparent, improving the parties' trust in the whole process.

\subsection{Supporting Decision Making}

Another important step in the conflict resolution process is the one of actual negotiation between the parts, in which they have to come up with concrete and valid outcomes, which may be rejected or potentially changed by the other part [22]. These outcomes should moreover encompass mutual gain in order to increase the chance of success [23]. In these step, several barriers can be identified. Sometimes people are simply unable be creative and invent potentially successful solutions. There are also people who avoid dealing with the conflict [20], because of previously unsuccessful experiences or simply for a matter of personality traits. These aspects can be strong enough to prevent parties from engaging in the negotiation process, and either drop the case or relegate it to their legal representatives.

The proposed conflict resolution platform provides means to overcome these barriers, namely through the generation of valid outcomes for the conflict and through the support for decisionmaking during the actual negotiation.

In what concerns the generation of solutions, an approach based on Genetic Algorithms was devised that creates a configurable amount of solutions whose utility ranges the whole search space. That is, a range of solutions that can satisfy one part or the other wholly as well as intermediate solutions that maximize mutual gain. The evaluation of utility is here of central importance. It encompasses both the economic value of the items in dispute as well as the subjective value that each party assigns each item, in order to increase the fairness of the solution. Indeed, we may prefer an item over the other for reasons other than its mere economic value.

This potentially large amount of possible outcomes can then be used in several ways: parties can explore them and analyze them in detail, the third neutral party can use them to support his work or an automated process can use them to support parties during the negotiation process.

UMCourt considers specifically the third approach. Indeed, the amount of information generated may be overwhelming for any of the parties, making its analysis inefficient. Nonetheless, an automated process can efficiently analyze it and provide the 
parties, in real-time with the best suited suggestion for an outcome.

The approach implemented in UMCourt starts by proposing the most likely outcome, which is estimated through the use of the information mentioned in the previous Sub-section. UMCourt proposes this outcome to the parties, while at the same time informing them that this is the outcome that maximizes their gain, according to its economic value and their preferences. Nonetheless, parties may not accept it. In that sense, UMCourt implements a negotiation mechanism based on the concept of a blackboard that allows parties to collaboratively work on a given proposal in an attempt to reach an agreement. If such is not possible, UMCourt proposes the following best suited outcome, on which parties can start to work again. This process repeats until either the parties reach an agreement or abandon the process.

An interface is provided to support this interaction between the parties, shown in Figure 4. It shows the current proposal, the answers of the parties, how much proposals the system has left, among other aspects. Additional interfaces exist that are not included here.

The generation and proposal of valid outcomes is one of the most important aspects in improving citizen access to justice. The use of such approaches empowers parties in their participation in the conflict resolution process, helping them in the process of creating and working over valid solutions. This is especially important in those cases in which parties show an avoiding conflict handling style or simply lack the creativity or other skills for coming up with valid and useful solutions for their conflict.

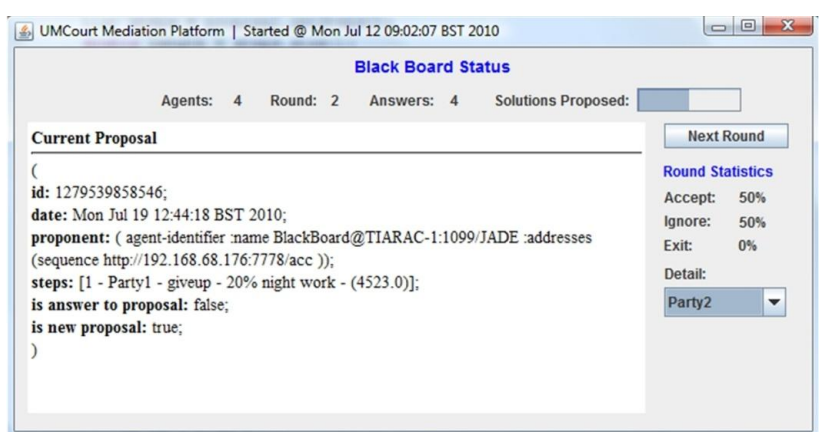

Figure 4. One of the interfaces for supporting negotiation.

\subsection{Including Contextual Information}

During the work carried out in the previously mentioned TIARAC project one particular issue was identified as being particularly negative in technology-supported conflict resolution: the lack of contextual information. Specifically, we found that people find it difficult to communicate efficiently online since communication tools in this domain rely mostly on e-mail, chat and other textbased approaches [14].

Indeed, when we communicate face-to-face we make use of much more than our words, employing aspects such as intonation, rhythm, body language or gestures to better convey our message and provide feedback for the messages received. The fact that such is currently impossible in ODR tools makes it difficult to communicate properly, especially when one considers that conflict resolution is really about communicating, arguing, convincing and understanding the other's state. For these reasons, people are often uncomfortable communicating online and prefer to do it face-to-face. The third neutral, in particular, may find it very difficult to estimate the state of the parties: how stressed they are, how anxious, how fatigued. This information is indeed important for him to take the best decisions, such as he uses it when meeting face-to-face with the parties. Common actions include postponing dealing with a given issue if the parties are too stressed, making a pause if they are showing signs of tiredness, among others. The analysis of this kind of information by the third neutral is impossible nowadays.

With these issues in mind we developed a group of functionalities aimed at improving the contextual information available in an ODR platform. Specifically, we devised non-intrusive ways of quantifying stress, fatigue and personal conflict handling style.

Concerning the first two, they are assessed from the analysis of the interaction patterns of the user with the ODR platform. Indeed, in a series of studies carried out we have established that our interaction with technological devices changes when we are stressed or fatigued. In this context, interaction is defined by features such as the velocity or acceleration of the mouse, the writing speed, the time a key is pressed down while typing, the duration of clicks or double clicks, how much in a straight line the mouse moves, among others.

The studies carried out show that, when under stress, the performance of the interaction tends to increase, evidenced through a more efficient movement of the mouse (e.g. in more straight lines, with less excess of movement) and more efficient use of the keyboard (e.g. faster writing speed, less key-down time).

Concerning fatigue the results attained point, as expected, the other way around, i.e., towards a decrease in the efficiency. Indeed, we have observed statistically significant differences between the interaction patterns of users when they are tired and when they are not.

However, more interestingly than these results, is the fact that we can indeed quantify two of the most important aspects of a user in real-time, in a transparent and non-intrusive way, by simply analyzing the interaction of the users with the computer.

Finally, we also include in this contextual information the personal conflict handling style [20], which we classify as 5 main types: Avoiding, Accommodating, Compromising, Collaborating and Competing. During the negotiation process we observe the behavior of the parties and the utility of the proposals they exchange. This utility, when framed within the boundaries described in sub-section 4.1, allows an idea of the behavior of the user towards the negotiation. If they consistently propose outcomes whose values are near or above their BATNA they are clearly being competitive, and vice-versa. Figure 5 depicts the classification of the conflict handling styles from the utility of the proposals exchanged in more detail. 


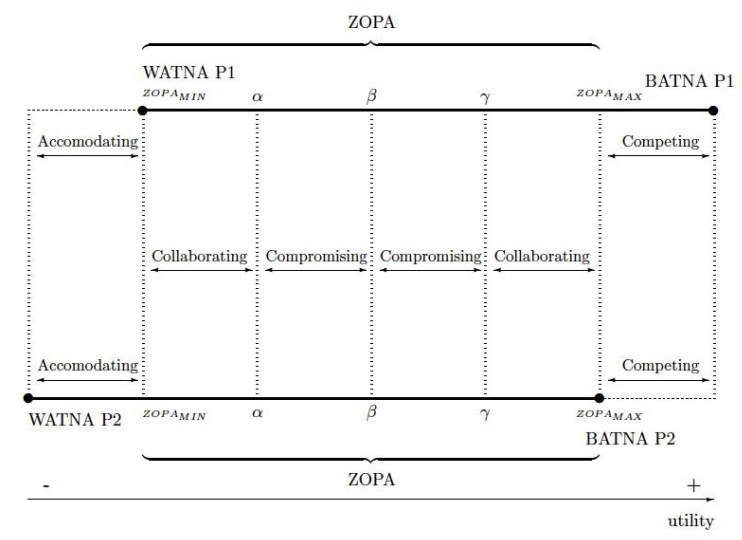

Figure 5. Mapping the utility of the proposal of a party into a specific conflict handling style.

The cold and impersonal nature of ODR tools may be seen as positive by some but it may also be otherwise, as it hinders communication which is central for the success of the conflict resolution process. The neutrals, in particular, find it much more difficult to take good decisions when they lack access to important contextual information about the parties. It is our conviction that the development of better communication tools, closer to our face-to-face communication process, will contribute to better and richer conflict resolution tools that will be better accepted by disputing parties and neutrals alike.

\subsection{Decreasing Costs}

When thinking about the costs of conflict one tends to focus exclusively on the economic costs. These, although significant, are not the only ones. In general terms, costs associated to conflict and its resolution can be broken down into four main categories: (1) direct costs; (2) productivity costs; (3) continuity costs; and (4) emotional costs.

Direct costs include all those costs that stem directly from the use of a conflict resolution tool, be it litigation in the courtroom (e.g., fees of lawyers, clerk, administration, security, legal staff, support staff, court reporter, etc.) or following an alternative approach (e.g. fees of third neutral, fees of using ODR tool, fee for accessing technology). Additional costs can also be included in this category, such as the cost of traveling, feeding and housing, especially when parties must go to a court in a geographical distant location.

Productivity costs include the value that one does not produce by being involved in the conflict resolution process. That is, if I spend 20 hours involved in solving the conflict, I am losing the value of what I would produce during those 20 hours. These may encompass further losses, particularly for the organization that employs the individual.

Continuity costs encompass the costs that result from being stuck in the conflict and include the cost of damaged relationships or of damaged external image, particularly important for organizations that rely on public image.

Finally, emotional costs encompass a wide range of effects that stem from dealing, for a potentially prolonged period of time, with negative emotions. These effects can spread from the emotional sphere to the physiological and mental one as negative emotions give way to anxiety, stress and other negative manifestations with effect on the body and the mind. Ultimately, these can impact health negatively to the point of triggering stress-related diseases, that translate in costs that stem from absenteeism, sick leave or disability claims.

Conflict resolution tools such as the one described in this paper can have a significant positive effect on the four categories of costs. Concerning direct costs, the use of such approaches would decrease or eliminate the need for parties to meet in a specific courtroom, with a significant positive impact on the aforementioned costs of litigation and transportation. It must nonetheless be mentioned that the use of an ODR tool may encompass certain costs that cannot be ignored.

Productivity costs can also be significantly decreased with the use of such approaches especially because, by being undertaken online, can be engaged in from any location with internet access. Ideally, the individual involved in a technology-supported conflict resolution could regularly participate in the process from his own workplace, decreasing the productivity losses associated with absenteeism.

Continuity costs would be decrease with the use of such tools in the sense that technology-supported conflict resolution tends to last less than traditional litigation. It is also a generally more cooperative environment, in opposition to the courtroom in which parties are placed against each other in a clear competitive and win-lose scenario. All this reflects positively on the maintenance of better interpersonal relationships between the parties. Moreover, such approaches decrease the costs associated to negative public exposure by being private rather than public such as litigation.

Emotional costs can be decreased in the sense that, when using technology, parties are separated. They do not have to necessarily meet in person. Moreover, by using asynchronous means, parties can reflect better on what they say each other and are less impulsive. All this results in a more positive environment for conflict resolution, potentially less weary than the courtroom.

\section{CONCLUSIONS}

Despite being considered a basic human right, access to justice is not always granted. Certain slices of the population face particular barriers, such as the poor, immigrants, women in certain cultures, children or people with certain disabilities. Nonetheless, in this paper we do not focus on such extreme cases. In fact, even the "average" individual in a developed country may face certain barriers that prevent his access to justice and conflict resolution.

In this paper we have analyzed some of these barriers, which include the costs of litigation (which often surpass the value of the items in dispute) and the duration of the whole process (which frequently lasts for months or even years). We have analyzed how the so-called Online Dispute Resolution tools can have a role in addressing these issues and, therefore, in overcoming some of these significant barriers. Nonetheless, even these new approaches, in their current form, have disadvantages and barriers of their own. Thus being, we relied on the analysis of a recently developed conflict resolution platform - UMCourt, to show how insights from Intelligent Systems and appropriate research directions can be used to improve them. Particularly, we addressed the following issues: (1) providing access to more and important information to improve the whole experience and empower the parties; (2) supporting decision making, especially during the actual negotiation phase, with the generation of optimal outcomes; (3) inclusion of contextual information to improve otherwise cold and impersonal communication mechanisms so as to make them closer to face-to-face communication; and (4) 
decreasing general costs associated to conflict resolution through the use of technology supported conflict resolution.

We are thus convinced that such approaches constitute a valid and interesting path to improve citizen's access to justice. Citizens who live far from services (e.g. rural areas) or citizens with poor access to information or resources can profit especially from such approaches. Nonetheless, and particularly in the ongoing scenario of economic crisis, everyone involved in conflict resolution might find it easier to solve conflict, partially or wholly with the support of technological tools.

\section{ACKNOWLEDGMENTS}

This work is part-funded by ERDF - European Regional Development Fund through the COMPETE Programme (operational programme for competitiveness) and by National Funds through the FCT - Fundação para a Ciência e a Tecnologia (Portuguese Foundation for Science and Technology) within projects FCOMP-01-0124-FEDER-028980 (PTDC/EEISII/1386/ 2012) and PEst-OE/EEI/UI0752/2014.

\section{REFERENCES}

[1] Brown, H., and Marriott, A. 2012. ADR: Principles and Practice. Sweet \& Maxwell, $3^{\text {rd }}$ edition.

[2] Cappelletti, M. 1993. Alternative Dispute Resolution Processes within the Framework of the World-Wide Accessto-Justice Movement. The Modern Law Review, Vol. 56, No. 3, Dispute Resolution. Civil Justice and Its Alternatives, pp. 282-296, Wiley

[3] Thiessen, E., and Zeleznikow, J. 2004. Technical aspects of online dispute resolution challenges and opportunities. Melissa Conley Tyler, Ethan Katsh, and Daewon Choi, eds, Proceedings of the Third Annual Forum on Online Dispute Resolution.

[4] Rhode, D.L. 2005. Access to Justice. Oxford University Press.

[5] Meeker, J.W. and Dombrink, J. 1993. Access to the Civil Courts for Those of Low and Moderate Means. 66 Southern California Law Review 2217

[6] Meena, J. 2012. Barriers to Women's Access to Justice in Haiti. 15 CUNY Law Review 27

[7] Goodman, J.W. 2003. The pros and cons of online dispute resolution: an assessment of cyber-mediation websites, in Duke Law and Technology Review pp. 1--16.

[8] De Vries, B.R.., Leenes, R. and Zeleznikow, J. 2005. Fundamentals of providing negotiation support online: the need for developing BATNAs. Proceedings of the Second International ODR Workshop, Tilburg, Wolf Legal Publishers pp. 59-67.

[9] Chiti, G. and Peruginelli, G. 2002. Artificial intelligence in alternative dispute resolution. Proceedings of LEA, pp. 97104.

[10] Brazier, T., Jonker, M. and Treur, J. 1998. Principles of Compositional Multi-agent System Development. In Proceedings of the 15th IFIP World Computer Congress, WCC98, Conference on Information Technology and Knowledge Systems, pp. 347-360.
[11] Muecke, N., Stranieri, A. and Miller, C. 2008. The integration of online dispute resolution and decision support systems. Expanding the horizons of ODR, Proceedings of the 5th International Workshop on Online Dispute Resolution (ODR Workshop'08), Firenze, Italy pp. 62-72.

[12] Van Der Hoek, W., and Wooldridge, M. 2008. Multi-agent systems. Handbook of Knowledge Representation, pp. 887928.

[13] Bellifemine, F. L., Caire, G., and Greenwood, D. 2007. Developing Multi-Agent Systems with JADE (Wiley Series in Agent Technology). Wiley.

[14] Carneiro, D, Novais, P, Neves, J. 2014. Conflict Resolution and its Context: From the Analysis of Behavioural Patterns to Efficient Decision-Making. Law, Governance and Technology Series, vol. 18, Springer. ISBN 978-3-31906238-9.

[15] Notini J., 2005. Effective Alternatives Analysis in Mediation: "BATNA/WATNA" Analysis Demystified, (http://www.mediate.com/articles/notinil.cfm), $<$ accessed July, 2014>

[16] Raiffa H. 1982. The art and science of negotiation: how to resolve conflicts and get the best out of bargaining, Cambridge, The Belknap Press of Harvard University Press.

[17] Steenbergen W. 2005. Rationalizing Dispute Resolution: from best alternative to the most likely one, Proceedings of $3^{\text {rd }}$ ODR Workshop, Brussels.

[18] Carneiro, D., Novais, P., Andrade, F., Zeleznikow, J. and Neves, J. Using Case Based Reasoning and Principled Negotiation to provide Decision Support for Dispute Resolution, Knowledge and Information Systems Journal, Springer, ISSN: 0219-1377, Vol 36, 3, pp 789-826, 2013.

[19] Andrade, F., Novais, P., Carneiro, D., Zeleznikow, J. 2010. Neves J., Using BATNAs and WATNAs in Online Dispute Resolution, in New Frontiers in Artificial Intelligence, Revised Selected Papers - JURISIN, Springer - LNAI 6284, ISBN 978-3-642-14887-3, pp. 5--18.

[20] Thomas, K. and Kilmann, R. 1974. Conflict and Conflict Management. http://www.kilmann.com/conflict.html Accessed in: 07/2010

[21] Nixon, P. G., Koutrakou, V. N., and Rawal, R. (Eds.). 2010. Understanding e-government in Europe: issues and challenges. Routledge.

[22] Stranieri, A., Zeleznikow, J. 2000. Tools for intelligent decision support system development in the legal domain. ICTAI pp. 186-189.

[23] Kuchar, J. K., Yang, L. C. 2000. A review of conflict detection and resolution modeling methods. Intelligent Transportation Systems, IEEE Transactions on, 1(4), 179189.

[24] Carneiro, D., Novais, P., Andrade, F., Zeleznikow, J., Neves, J. (2014). Online dispute resolution: an artificial intelligence perspective, Artificial Intelligence Review, Springer, ISSN: 0269-2821, February 2014, Volume 41, Issue 2, pp 211-240. 